\title{
Understanding cultural aspects of deaf communities in México towards the codesign of automatic sign language processing systems
}

\author{
Soraia Silva Prietch (iD [ Universidade Federal de Rondonópolis | soraia@ufr.edu.br ] \\ J. Alfredo Sánchez ${ }^{10}$ [ Laboratorio Nacional de Informática Avanzada | alfredo.sanchez@lania.edu.mx ] \\ Josefina Guerrero García (DD [ Benemérita Universidad Autónoma de Puebla | josefina.guerrero@correo.buap.mx ]
}

\begin{abstract}
This paper reports findings from a study through which we seek to understand the socio-economic and cultural context of deaf communities in a city in México in order to inform the codesign of automatic sign language processing systems. We conducted eleven interviews in two school settings with three deaf persons who are sign language users and eight hearing persons who have close relationships with deaf persons. We designed interview scripts to collect data from deaf persons, parents, and sign language teachers and interpreters. In addition to demographic data, we collected data on experience with technology for communication use as well as salient cultural aspects. Key findings from our research relate to perceptions of study participants about themselves and their context: Socio-economic aspects are consistent with previous studies; cultural traits are central for communication, denote a strong sense of identity, and highlight the role of sight and perception. We also report on reflections that were facilitated by the application of existing schemes and frameworks, which allowed us to learn about communication hardships and workarounds, as well as the most important values for the community. These findings shed light on a path we want to further investigate, which aims to understand whether variations exist in the basic needs of deaf signers with respect to the codesign of ASLP systems, independently of the countries where they live.
\end{abstract}

Keywords: Deaf signers, Assistive technology, Culture, Values, Community

\section{Introduction}

Supporting the deaf ${ }^{1}$ community and conducting research involving sign language (SL) entail quite specific considerations. According to Bragg et al. (2020), "designing, building, and evaluating sign language interfaces present compelling and timely research challenges, and require collaborative efforts." In our previous research, we raised a few challenges, including some in technical and assistive technology systems (e.g., large public SL database, recognition, classification and data extraction algorithms); linguistics (e.g., SL specific grammar, classifiers communication, domain specific jargon, regionalisms); and human and context aspects (e.g., diversity within deaf culture, cultural aspects within a community, a country and among different countries, educational background). These challenges place our research on SL in a multidisciplinary scenario, in which we are interested in investigating human and context issues intrinsic to the codesign of automatic sign language processing (ASLP) systems.

Following Bragg et al. (2019), we use the term "ASLP systems" to refer to automatic systems designed to recognize and to generate sign language, as well as to translate to and from sign language. Also, we regard ASLP systems as assistive technology (AT) products (Shinohara and Wobbrock (2011); Brazil (2015)) to support communication among signers and non-signers. However, we consider that these systems have a broader perspective as a universal design
(UD) solution, since they also assist (non-signers) hearing persons to understand what deaf signers communicate.

Shinohara and Wobbrock (2011) note one of the reasons assistive technology products have high rates of abandonment is the fact that many draw negative attention towards the user, since AT products are built specifically for persons with disabilities (PwD). In a complementary view, the HAAT model (Cook and Polgar (2008)) highlights the importance of designing, building, and evaluating all aspects related to "Human, Activity, Assistive Technology and Context". We understand that not only technical aspects define the adoption or abandonment of technology. By designing an AT based on UD principles, we aim to provide an inclusive interface for communication among a broader group of people (in this case, signers and non-signers) who wish to interact in diverse contexts.

The findings presented in this paper, however significant, are but initial results of a larger project, in which we aim to compare results from research conducted in Brazil and Mexico, applying reproducible methods and techniques with similar stakeholders' profile. With this broader goal in mind, we focused on the problem of determining, whether variations exist in the basic needs of communities of deaf signers (deaf persons who are SL users), considering the countries where they live, in the process of codesigning ASLP systems. This paper addresses findings regarding deaf culture mainly on the Mexican side. We do include initial observations from the Brazilian side, but a later stage will address comparisons more formally with a Brazilian setting.

\footnotetext{
${ }^{1}$ In this paper, we are not using capitalized $\mathrm{D}$ or lowercase $\mathrm{d}$ to distinguish writing of the word deaf, since we understand deaf culture is diverse and includes people who communicate using different modes, such as, sign language, reading/writing, lip reading/ oralization. This means there are many subcultures within it, those who take into account the sociocultural model, or those who follow the medical model, among other models.
} 
We report on our efforts to strengthen ties with a deaf community and to understand the socio-economic and cultural context of deaf communities in México. Within these communities, we found stakeholders who have been invited to participate as codesigners of ASLP systems.

\section{Deaf culture in Mexico}

The Mexican National School of Deaf-Mute (Escuela Nacional de Sordomudos, ENS) was founded by Eduardo Huet in 1867 (Cruz-Aldrete and Serrano, 2018), and evidence indicates it was the place where LSM, the Mexico's official SL originated. The creation of civil associations for the deaf dates to the 1980 s with the goal of strengthening community ties and promoting SL education. Teaching SL through religious prayers is a common practice that began in the early 20th century (mostly using signed Spanish), when the ENS ceased its activities.

In 2005, the General Law of Persons with Disabilities (México, 2005) recognized ${ }^{2}$ the SL as an official mode of communication of the deaf community in México. The 2010 census (INEGI, 2010) reports that $12.1 \%$ persons among those with disabilities claimed to be deaf in Mexico (close to 700 thousand people). However, this figure does not provide information on the use of SL (Cruz-Aldrete and Serrano (2018)). Analogously, Bragg et al. (2020) report that the USA census includes ASL as a separate mode of communication, but also does not collect data on the number of ASL signers.

Even though LSM is the most used language by deaf signers in Mexico, it is not the only SL in the country. Cruz-Aldrete and Serrano (2018) conducted a study in four Mexican states on cultural aspects of deaf community that evidence a plurilingual diversity in modes of communication, including the use of three SLs: LSM, ASL (American Sign Language) - especially for deaf communities who live in the Mexico-US border-, and LSMy (LSM-Maya Sign Language). Also, SLs are used in rural areas. Thus, SLs are influenced by written and spoken languages such as Spanish, English, and indigenous languages (68 languages are spoken in Mexico besides Spanish).

From Cruz-Aldrete (2008), we can easily observe traces of the dominant oral language in LSM, mainly due to its historical context and the initial use of signed Spanish. For example, when articles and prepositions are used, LSM relies on their initials in Spanish (e.g., LA, DE). Also, the initial letter of Spanish words is often the basis for hand configurations of various LSM signs (e.g., CAMA, MAMÁ). This is not specific to LSM, as it can also be observed in other sign languages around the world (e.g., ASL and Libras).

\section{Cultural aspects in technology design}

For Hall (1990), “culture controls behavior in deep and persisting ways, many of which are outside of awareness and therefore beyond conscious control of the individual". According to this author, it is impossible to teach culture to outsiders in the way locals could teach how to communicate in their language. Still, language is one of the most important aspects within a culture. In order to achieve understanding, one must be immersed in the culture, living it, talking to people, observing, engaging in day-to-day activities, and reflecting on how similar or different is this other culture compared to oneself's. Hall (1990) argues that "humans experience things on three different levels [...]: formal, informal, and technical". The formal level states rules and norms, defining what is right or wrong, and it is associated with emotions (e.g., "alternative ways of behavior are thought of as unnatural" (Hall, 1990). The informal level carries learnt behavior (e.g., by following a model) that may become patterns that people may not be aware of in a given group, community, or country. In the technical level directions typically are passed on in an explicit manner, having fully conscious behavior (e.g., instructions from a teacher to a student). These three levels are integrated, since "while one will dominate, all three are present in any given situation" (Hall, 1990). Supported by the concept of the three culture levels, Stamper et al. (2000) proposed a layered representation of the design of information systems within organizations. In this representation, the three levels are considered to conduct design. At the center, the technical system is, covered successively by the formal layer and the informal layer. From this perspective, many studies have been conducted (Baranauskas (2009); Pereira and Baranauskas (2015); Paim, Prietch and Duarte (2018); Paim and Prietch (2019a); Paim and Prietch (2019b)).

Another study perspective on cultural aspects for technology design, proposed by Salgado, Leitão and De Souza (2013), is called Cultural Viewpoint Metaphors (CVM). Building on Semiotic Engineering ${ }^{3}, \mathrm{CVM}$ is a "conceptual design tool to help organize the HCI [Human-Computer Interaction] designers' communication of culture-sensitive interaction with/through computer systems". CVM comprises five metaphors, materialized as interface signs and interaction forms, which are mapped into a continuum of cultural approximation: (i) the domestic traveler metaphor, which considers only the local culture; (ii) the observer at a distance, which provides superficial awareness of other cultures; (iii) the guided tour visitor, which delivers selected aspects of other cultures; (iv) the foreigner with translator metaphors, which represents aspects of other cultures provided in the native language of the users; and (v) the foreigner without translator metaphor, which allows the users to fully experience an immersion into another culture.

As CVM is conceived as an epistemic tool to better understand the designers' communication with the users through cross-cultural interfaces and their ways of interacting, we envision ASLP technology as a cross-cultural system that is designed as a means of communication between SL users (signers) and non-users (non-signers) in the same

\footnotetext{
2 "Implement the official recognition of the Mexican Sign Language and the Braille Writing System, as well as training, communication, and research programs, for use in the National Educational System;" (Chapter III, Art. 10, X)

3 de Souza, C. S. (1993). The semiotic engineering of user interface languages. International Journal of Man-Machine Studies, 39 (5), $753-773$.
} 
Table 1. Profile of the eleven respondents.

\begin{tabular}{lcccccccccccc}
\hline \hline & P1 & P2 & P3 & P4 & P5 & P6 & P7 & P8 & P9 & P10 & P11 \\
\hline $\begin{array}{l}\text { Deaf (D) and hear- } \\
\text { ing (H) persons }\end{array}$ & D & D & D & H & H & H & H & H & H & H & H \\
$\begin{array}{l}\text { Teachers (T) and } \\
\text { interpreter (I) }\end{array}$ & T & T & - & - & - & - & - & - & T & I & T \\
$\begin{array}{l}\text { Hearing parents of } \\
\text { deaf individuals }\end{array}$ & - & - & - & $\checkmark$ & $\checkmark$ & $\checkmark$ & $\checkmark$ & $\checkmark$ & - & - & - \\
$\begin{array}{l}\text { From special } \\
\text { school 1 or 2 }\end{array}$ & 1 & 1 & 1 & 1 & 1 & 2 & 2 & 2 & 1 & 1 & 2 \\
\hline
\end{tabular}

country. Here, we are taking discussions of Gugenheimer et al. (2017) to support our understanding of considering potential deaf and hearing users of an ASLP system from a same country as a cross-cultural approach.

Gugenheimer et al. (2017) relied on the Co-Cultural Theory ${ }^{4}$ throughout the design and evaluation process of an automatic sign language translation (ASLT) system to mediate communication between signers and non-signers. The authors "identified the Deaf as a subordinate group in the hearing-dominated society". They state the importance of understanding the social norms of both groups (deaf and hearing persons), since this type of AT product may influence negatively the communication quality, leading to technology abandonment or continuance of group segregation. Gugenheimer et al. (2017) found that conversation breaks and emphases of deficiency that may not be related to technology can occur during an attempt of communication between signer and non-signers. These negative aspects must be taken into consideration when analyzing context. Communication breaks can be content-related (e.g., misunderstanding the other person's message) and norm-related (e.g., occur when differences in cultural ways of being are unknown or disrespected by the other). With respect to the emphasis of deficiency, the use of an ASLT system can cause discomfort for deaf persons when they are placed in a position where communication is dependent on technology.

Moreover, Pereira and Baranauskas (2015) present the Value-oriented and Culturally Informed Approach (VCIA) to design interactive systems. VCIA is based upon the Organizational Semiotics theory ${ }^{5}$, the Building Blocks of Culture (Hall, 1990), and the Socially Aware Computing approach to design (Baranauskas, 2009). VCIA provides artifacts and methods for researchers to take into consideration human values from beginning to end of the HCI design life cycle.

In this paper, we explore how interested parties understand the continuum of cultural approximation in different real-life situations - include considering deaf and hearing peers as potential codesigners of the technology - and suggest how an ASLP system can function as an interface and as a mean to facilitate human-to-human communication in these scenarios. We also use the general concept of VCIA to identify the values of the interviewed participants considering that they are stakeholders of ASLP systems.

\section{Methodology}

As one of the research goals, we aimed to strengthen the ties with a deaf community. In order to accomplish this, we have been participating in activities in the local deaf communities' agenda, such as taking LSM lessons (for the past six months in remote learning mode), attending lectures and workshops given by deaf signers, observing deaf students in classes, and engaging in social events with the deaf community (e.g., going to the movies ${ }^{6}$ with a group of deaf students and, deaf and hearing teachers). These activities are essential to the research for many reasons: to build a bond with community, to become a familiar face in their environment for them to carry on their regular activities without having to change behavior due to the presence of outside observers, to show respect for deaf culture and language, and to understand the daily activities in the context and the relationships among individuals.

During December 2019, and January 2020, we conducted eleven interviews in two school settings with three deaf persons who are SL users, one SL interpreter, five hearing parents of deaf individuals, and two hearing teachers of deaf students. The recruitment of participants was arranged by an interpreter in one school and by a teacher in the other. The interview with deaf persons was mediated by two different LSM interpreters who gave voice to participants. The research project was approved by a Brazilian University Ethics Committee (CAAE 18708619.2.0000.8088), which included the complete project and the informed consent in both languages: Portuguese and Spanish. Since in Mexico still there is no legislation on ethics in research with humans, we did not need multicentric protocols. All participants were adults and signed the Spanish version of the informed consent. In total, we had nine hours of transcribed interviews. Table 1 offers an overview of the eleven respondents' profiles.

We designed three different interview scripts: (i) deaf participant, (ii) deaf persons' family, and (iii) deaf persons' teacher and interpreter. All scripts contained the same parts with a different number of questions: Part I, demographic data (Prietch and Filgueiras (2013); Kacorri et al. (2015));

\footnotetext{
${ }^{4}$ Orbe, Mark. 1998. Constructing co-cultural theory: An explication of culture, power, and communication. Sage.

${ }^{5}$ Liu, K., 2000. Semiotics in Information Systems Engineering. Cambridge University Press.

6 The movie "No hay límites" was produced by a deaf director, Alex Gallardo, who also gave a talk on site after the projection.
} 
Part II, basic experience of technology for communication use; and Part III, cultural aspects (Salgado, Leitão e de Souza (2013) and Pereira and Baranauskas (2015)). The full questionnaire by Kacorri et al. (2015) was used only in the interview script for deaf participants, whereas in the case of families some participants were asked to report about their children.

The interviews were conducted individually, and we asked every participant to provide their name sign (seña personal) (Cruz-Aldrete, 2008) after the informed consent was signed. 'In deaf communities, a 'name sign' is a lexical form used to identify a specific person or place. Name signs are important identity markers because they denote membership in deaf communities for both deaf and hearing people" (Petitta et al. (2018)). This was important to establish rapport between researchers and participants, to show that researchers had previous contact with other deaf communities and to avoid repeatedly fingerspelling the names of the persons in the room.

\section{Findings}

Regarding deaf respondents (Table 2), several aspects stand out. Their name sign can be classified as the combination type, since the sign is produced with their name initial and a representation of some physical trait (Petitta et al. (2018)). Two were female and one male, ages averaging 34.33, all describing themselves as being deaf and reporting they are deaf by birth. No one else in their family is deaf and, for that matter, one participant reported to use only mimicry, a second one uses mimicry and some oralization, and a third one uses a few signs and oralization with her mother to communicate with family members.

On their school type, two participants attended mainstream school, whereas another attended a so-called "multiple attention center" (MAC); two of them mentioned they use LSM at school, the participant who studied at MAC reported to communicate frequently in SL. Two have not finished high school yet, and one is a college graduate.

As for communication modes, they report an average of 17.33 years since they began to learn LSM, and self-rate their current LSM knowledge as 7, 8 and 8 (in a 1 to 10 scale). They use written language at home at a basic level, the two participants who are employees have to read and write in Spanish regularly and both use LSM at work most of the time - they are teachers in one of the schools we visited. Since we asked, they self-rated their writing skills as 3,7 and 7, and reading skills as 4, 6 and 10 (all in a ten-point scale), where the highest grade was reported by the deaf student compared to the other two deaf teachers who were interviewed.

Table 2. Demographic data based on Kacorri et al. (2015)'s questions.

\begin{tabular}{|c|c|c|c|c|c|c|c|c|}
\hline & $\mathrm{P} 1$ & $\mathrm{P} 2$ & P3 & $\mathrm{P} 4 *$ & P5* & P6* & $\mathrm{P} 7 *$ & P8* \\
\hline Gender & $\mathrm{M}$ & $\mathrm{F}$ & $\mathrm{F}$ & $\mathrm{F}$ & $\mathrm{F}$ & $\mathrm{F}$ & $\mathrm{F}$ & $\mathrm{F}$ \\
\hline Age & 52 & 32 & 19 & 24 & 31 & 5 & 5 & 3 \\
\hline $\begin{array}{l}\text { Self-describe as } \\
\text { (deaf) }\end{array}$ & deaf & deaf & deaf & - & - & - & - & - \\
\hline $\begin{array}{l}\text { When became } \\
\text { (deaf) (Since birth) }\end{array}$ & SB & SB & SB & SB & SB & SB & SB & SB \\
\hline $\begin{array}{l}\text { When learned SL } \\
\text { (age) }\end{array}$ & 20 & 10 & 6 & 2 & 24 & 4 & 3 & 2 \\
\hline Parents are (deaf) & No & No & No & No & No & No & No & No \\
\hline $\begin{array}{l}\text { Parents use SL } \\
\text { (basic, advanced) }\end{array}$ & No & No & Yes (b) & Yes (a) & Yes (b) & Yes (b) & Yes (b) & Yes (b) \\
\hline $\begin{array}{l}\text { School type (DS = } \\
\text { daytime school for } \\
\text { deaf students; MS } \\
=\text { a mainstream } \\
\text { school) }\end{array}$ & MS & MS & DS & DS & MS & DS & DS & DS \\
\hline $\begin{array}{l}\text { School SL (basic, } \\
\text { advanced) }\end{array}$ & Yes (b) & No & Yes (a) & Yes (a) & No & Yes (a) & Yes (a) & Yes (a) \\
\hline $\begin{array}{l}\text { Education (did not } \\
\text { graduate high } \\
\text { school, graduated } \\
\text { college) }\end{array}$ & nHS & GC & nHS & nHS & nHS & nHS & nHS & nHS \\
\hline $\begin{array}{l}\text { Home SL (spouse, } \\
\text { children, mother) }\end{array}$ & No & Yes $(s, c)$ & Yes (m) & Yes (c) & Yes (c) & Yes (c) & Yes (c) & Yes (c) \\
\hline $\begin{array}{l}\text { Home Spanish } \\
\text { (basic, advanced) }\end{array}$ & Yes (b) & Yes (b) & Yes (b) & Yes (b) & Yes (b) & No & No & No \\
\hline Work SL & Yes & Yes & - & - & - & - & - & - \\
\hline Work Spanish & Yes & Yes & - & - & - & - & - & - \\
\hline
\end{tabular}

* Hearing parents (participants P4 to P8) answered these questions about their deaf children. 
With respect to hearing parents of deaf individuals, we interviewed four mothers and one father, with an age average of 39.6. One has a combination type of name sign, one has a description type ("describe a characteristic of a person" (Petitta et al., 2018), two said they did not remember, and one did not have a name sign yet. The average age of their born deaf children is 13.67. Two parents reported having other family members who are deaf (e.g., cousin, uncle, husband's relatives). Three mentioned having basic knowledge of LSM (self-rated as 5, 6 and 7), one has been using LSM for 23 years (selfrated as 7) and one is just beginning to study LSM (selfrated as 1). In order to communicate with their children, two use LSM, two only pointing and mimicking, and one LSM and writing. Two did and two did not finish high school, and one finished technical education after high school. Three are currently working, two of them at one of the visited schools. None of these parents were related to the deaf participants.

Also, we interviewed two hearing female teachers and one male interpreter who have close and frequent contact with deaf persons. Their name sign can be classified as the combination type. Their age average is 26.33 , one graduated from college in special education and two are currently attending college, majoring in Psychology, one teacher has ten years of experience (one and a half with deaf students), one teacher has 14 months of experience with deaf students, and the interpreter has four years of experience. One teacher mentioned having a deaf cousin in her family. Their selfgrades of their LSM skills are 5, 6 and 8 .

In addition to demographic data questionnaires, we also asked questions that could provide some socio-economic and cultural insights about respondents. In Table 3, we present summarized data and discuss them below.

When asked about their race or ethnicity, nine responded "Mexican," one answered he is a "dark colored Mexican", and one reported to be "Oaxacan" (someone who was born in the State of Oaxaca). Ten mentioned to have heterosexual orientation and one bisexual (the youngest participant). Nine reported to be catholic, one described himself as a believer, and one mentioned not practicing a religion.

About their income level, six answered their family could be regarded as middle class, one as lower middle class and one as lower class, with all of them living with two or more relatives in the same house. Six have two or more children, one parent having two deaf children out of five; the four single participants do not have children, one reported being in a stable union but does not live in the same house as children and spouse, and one is divorced and raises children on her own. None of the interviewed deaf participants receive financial support from the government, but four parents of deaf individuals mentioned having this support for their young children.

Table 3. Socioeconomics and cultural data about respondents.

\begin{tabular}{|c|c|c|c|c|c|c|c|c|c|c|c|}
\hline & $\mathrm{P} 1$ & $\mathrm{P} 2$ & P3 & $\mathrm{P} 4$ & P5 & P6 & P7 & P8 & P9 & P10 & $\mathrm{P} 11$ \\
\hline $\begin{array}{l}\text { Race or ethnicity } \\
\text { (Mexican, Oaxacan) }\end{array}$ & M & M & M & M & M & M & M & M & $\mathrm{O}$ & M & M \\
\hline 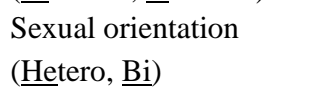 & $\mathrm{He}$ & $\mathrm{He}$ & $\mathrm{Bi}$ & $\mathrm{He}$ & $\mathrm{He}$ & $\mathrm{He}$ & $\mathrm{He}$ & $\mathrm{He}$ & $\mathrm{He}$ & $\mathrm{He}$ & $\mathrm{He}$ \\
\hline $\begin{array}{l}\text { Religion } \\
\text { (Catholic, Believer, } \\
\text { None) }\end{array}$ & $\mathrm{C}$ & $\mathrm{C}$ & $\mathrm{C}$ & $\mathrm{C}$ & $\mathrm{C}$ & $\mathrm{C}$ & $\mathrm{C}$ & $\mathrm{C}$ & $\mathrm{C}$ & $\mathrm{N}$ & B \\
\hline $\begin{array}{l}\text { Marital status } \\
\text { (single, consensual un- } \\
\text { ion, } \underline{\text { married, }} \text { divorced) } \\
\text { (Since birth) }\end{array}$ & $\mathrm{U}$ & M & $\mathrm{S}$ & $\mathrm{D}$ & M & M & M & M & $\mathrm{S}$ & $\mathrm{S}$ & $\mathrm{S}$ \\
\hline Number of children & 3 & 2 & 0 & 3 & 4 & 5 & 3 & 3 & 0 & 0 & 0 \\
\hline $\begin{array}{l}\text { Income level } \\
(\mathrm{M}=\text { middle, } \mathrm{LM}=\text { low } \\
\text { middle, } \mathrm{L}=\text { low })\end{array}$ & M & $\mathrm{L}$ & M & LM & $\mathrm{M}$ & M & M & M & - & - & - \\
\hline Number of residents & 6 & 9 & 3 & 4 & 3 & 4 & 5 & 5 & - & - & - \\
\hline $\begin{array}{l}\text { Financial support from } \\
\text { the government }\end{array}$ & - & - & - & - & Yes & Yes & Yes & Yes & - & - & - \\
\hline $\begin{array}{l}\text { Signwriting's aware- } \\
\text { ness of existence }\end{array}$ & - & Yes & - & - & - & - & - & - & - & Yes & Yes \\
\hline Smartphone owner & Yes & Yes & Yes & Yes & Yes & Yes & Yes & Yes & Yes & Yes & Yes \\
\hline $\begin{array}{l}\text { D/H communication } \\
\text { app }(0=\text { none, } 1=\text { insuf- } \\
\text { ficient, } 2=\text { regular, } \\
3=\text { good })\end{array}$ & 0 & 0 & 3 & 3 & 3 & 2 & 2 & 1 & 2 & 1 & 3 \\
\hline $\begin{array}{l}\text { ASLT's awareness of } \\
\text { existence }\end{array}$ & No & No & No & No & No & No & No & No & No & No & No \\
\hline
\end{tabular}


Also, only one deaf teacher, one hearing teacher and the hearing SL interpreter have heard about Signwriting, as a way of representing SL in a written form, but they have never used it. Whatsapp, Facebook and Instagram are the most used mobile applications for communication reported by the three deaf participants. To communicate with deaf persons, all hearing respondents mentioned to use short and simple text messaging, three reported to use video-call (LSM) and one also uses audio. Communication between deaf persons and hearing persons (D/H communication app) using an app on average was considered barely sufficient to insufficient to understand each other. None of the participants knew or had used any automatic sign language translator (ASLT).

The five most representative examples of cultural characteristics of Mexico for participants were categorized into five groups, which we ordered, from the most to the least cited: History and traditions (17), tourism (11), food (10), people (10), and sport (1). In Table 4, we summarize the respondents' answers by category of Mexico's cultural characteristics.

About the five most representative cultural characteristics of the deaf community in Mexico, participants reported examples that we categorized as: culture and communication (17), community awareness and identity (10), and visual attention and perception (8). In Table 5, we present the respondents' answers.

Using the continuum of cultural approximation scheme, the eleven participants reported their opinion for each of the five metaphors. Using the artifact we designed, adapted from Salgado, Leitão e de Souza (2013), deaf participants referred to their personal experience, whereas hearing participants expressed their point of view about their children or students. The artifact (Figure 1) presents images and text written in Spanish to facilitate explanation of the traveler metaphors. At the top of the artifact, a title asks participants to "Please, include examples of similar communication situations of the daily life of a Deaf person". Below that, we included five images with a short explanatory text. From left to right, in Image 1, we represent the Domestic traveler (You are in a place where you can communicate in LSM). In Image 2, the Observer at a distance (You are in a place and only receive information in LSM, you cannot interact). In Image 3, the Guided tour visitor (You are in a place with many people, and you get information in LSM). In Image 4, the Foreigner with translator metaphors (You are in a place with hearing persons, and you have an LSM interpreter); and, in Image 5, the Foreigner without translator metaphor (You are by yourself in a place and need to communicate in written or spoken language). At the bottom of each image, we asked participants "How do you feel (in this scenario)?" and five smiley faces representing emotions from sad to happy are the response options. At the center, blank spaces are available for respondents to include their answers.
Considering all participants, in the domestic traveler metaphor, deaf signers would communicate naturally everywhere among peers, such as, when they are at home or at their special school, or when traveling with other deaf persons. the observer at a distance, is a situation deaf signers live every day, as most of the time they are surrounded by hearing persons speaking, such as, during family meals, when there is no interpreter, or at movies (with subtitles) when they are unable to read. The guided tour visitor is a situation where deaf signers receive information, but they cannot respond directly, needing the assistance of an interpreter or a family member, such as when visiting a museum or an archaeological zone, or participating in a collective sport practice. In the foreigner with translator metaphors, deaf signers would count on a SL interpreter as a mediator of the communication, such as for bank transactions, job interviews, tourism, shopping, restaurant ordering. Opinions collected for the foreigner without translator metaphor include that deaf signers can communicate neither with hearing persons of a given country nor with deaf signers who use other SL in a foreign country. In this metaphor, the means of communication include mimicry, gestures, pointing, and short and simple written text.

Lastly, inspired by Pereira and Baranauskas (2015), we asked participants to report the five main values they believe are the most important in their lives, in an open-ended question. Participants mentioned the following: (7) respect, (5)

$\underline{\text { Table 4. Mexico's cultural characteristics according to respondents }}$

\begin{tabular}{|c|c|}
\hline Category & Respondents' answers \\
\hline $\begin{array}{l}\text { History and } \\
\text { traditions }\end{array}$ & $\begin{array}{l}\text { "History of China Poblana", "history", } \\
\text { "traditions" (3), "All-Saints' tradition", } \\
\text { "Day of the Dead" (2), "posadas", “dif- } \\
\text { ferent ethnicities and languages", "tala- } \\
\text { vera", "clothing”, "'architecture", "colo- } \\
\text { nial houses", "traditional dances", "pre- } \\
\text { hispanic culture"; "mariachis" }\end{array}$ \\
\hline Tourism & $\begin{array}{l}\text { "To know places", "tourism in different } \\
\text { states", "museums" (2), "Xochimilco", } \\
\text { "pyramids", "Cholula ( } 365 \text { churches)", } \\
\text { "take a walk in Puebla", "touristic } \\
\text { places", "geography (natural diversity)", } \\
\text { "biodiversity" }\end{array}$ \\
\hline Food & $\begin{array}{l}\text { "food with tortilla", "food" (2), "tacos", } \\
\text { "food (mole, chile en nogada, pozole)", } \\
\text { "gastronomy" (3), "cooking", "spicy } \\
\text { food" }\end{array}$ \\
\hline People & $\begin{array}{l}\text { "how people have fun drinking", "curs- } \\
\text { ing (saying names)", "they move their } \\
\text { hands", "they are party people", "pleas- } \\
\text { ant and communicative people", "lovely } \\
\text { people", "people's charisma", "close } \\
\text { minded"; "LSM"; "solidarity", }\end{array}$ \\
\hline Sport & "Soccer time" \\
\hline
\end{tabular}




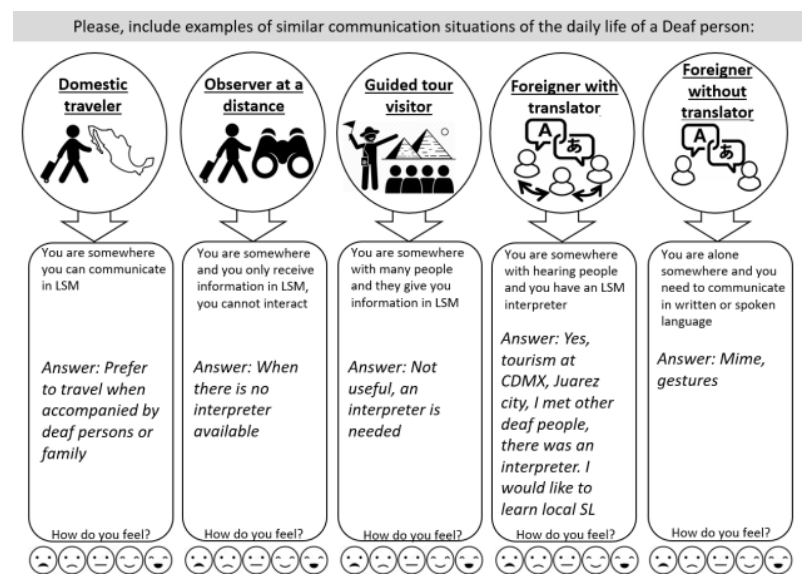

Figure 1. Cultural Viewpoint Metaphors artifact with one respondent's answers.

love, (4) discipline, (4) education, (3) honesty, (3) tolerance, (2) support. Other twenty-seven values were reported once each, such as bravery, empathy, equality and equity, "myself', and self-esteem.

\section{Discussion}

We analyze here the most salient implications of the findings reported in the previous section.

The combination name sign was the most common type, with seven participants and two researchers as representatives. The three deaf participants who reported having hearing parents and not using SL to communicate with members of their families, reported they use some isolated signs at home. Among the five hearing parents of deaf individuals, only one can fully communicate with her daughter in LSM; the others have only basic knowledge. The lack of close contact with SL users explains why three parents did not report their name signs. Humphries et al. (2019) note the large percentage $(96 \%)$ of deaf children of hearing parents and the need to learn SL as early as possible, preferably, learning together in order to promote a stronger bonding experience between them and to provide better chances for cognitive development, language acquisition, and literacy.

About literacy, in spite of two participants having reported medium to high reading (6 and 10) and writing skills (7 and 7), all three asked for the interpreter to sign the content of the informed consent form. This fact does not necessarily show they were not able to read, but rather that they have a stronger preference for using SL to make sense of content. On the other hand, other data we collected may support the idea of lower literacy than reported: communication at home through mimicry, gestures, and short and simple text, as well as their limited communication experiences due to environment inaccessibility reported on the Cultural Viewpoint Metaphors. The low literacy of people who are pre-linguistic deaf has been widely and deeply studied (Power and Leigh (2000); Dyer et al (2003)).

Three parents who reported to communicate with their children using basic LSM and, amongst them, two communicate through only pointing and mimicking, each have little children who are still learning LSM and are in the same class at school. Two reported to be learning LSM at the same pace as their children and the third parent also reported having a deaf teenage daughter. Three parents reported being currently working, and, in spite the five parents having mentioned to belong to a middle class (4), and in the lower middle class (1), two finished high-school, two concluded middle school and one obtained a technical training degree. Three parents have government financial support for low-income families, and one supports her family by herself and has three daughters. Directly asking about their income would have been too intrusive, however, even if it would make it easier to assign them to a category in the economic spectrum, since there is evidence of a correlation between disability and poverty status, especially in developing countries (CRPD (2006); Mirta, Posarac and Vick (2013)).

Although LSM has been recognized as an official language since 2005 in Mexico (México, 2005), well known universities still do not offer undergraduate programs on SL and do not have proficiency exams that state someone's level of knowledge for teaching or interpreting in SL. Examples include the interviewed professionals who took SL courses and are learning with the deaf community on the fly. Compared to Brazil, the first undergraduate programs ${ }^{7}$ with presential classes to train SL teachers and interpreters were established in 2006 and in 2008, respectively. Moreover, Pro$\operatorname{libras}^{8}$ is an official Brazilian SL proficiency exam, which certifies different levels of knowledge for teachers and interpreters, and state exams are available for those who seek to work locally.

Among our eight hearing participants, six reported the use short and simple text messaging to communicate with deaf persons they interact with daily. During a lecture of deaf Mexican computer scientist Jorge Santiago Jacinto, at one of the special schools we conducted interviews, he asked teachers "do you know how to communicate in other languages, besides Spanish?". When they replied "English," he asked teachers again "why did you not prefer to learn sign language?". Everyone was quiet, especially as they are teachers of deaf students. However, in this school, teachers are motivated to use Fitzgerald's key system ${ }^{9}$, which is known as an oral method for teaching written language to deaf students.

Regarding data on race or ethnicity, all participants answered in some way to be Mexican. It should be noted that it is not customary to inquire about race in Mexico, and that "Mexican" refers more to nationality than to racial or ethnic traits. Only one participant reported being "dark skinned." Since this was an open question, expected answers would relate to ancestry or skin color as it is most common in Brazil

\footnotetext{
${ }^{7}$ UFSC. Undergraduate programs on "Letras-Libras". https://libras.ufsc.br/libras-distancia/

8 Prolibras. t.ly/Q4ul

${ }^{9}$ Fitzgerald, Edith. Straight Language for the Deaf. Washington D.C. Volta Bureau, 1954.
} 
(IBGE, 2010). However, what we observe and understand from history, México is a country that did not have as much slavery of people from Africa (as Brazil did), thus miscegenation mainly occurred between the indigenous population and Europeans from Spain. Nowadays, discrimination still occurs towards minority races, because of which, among others, in 2018, México issued a Federal Law ${ }^{10}$ to prevent and to eliminate discrimination. We understand this historical context influences how individuals self-report their race or ethnicity.

Regarding sexual orientation, out of eleven participants, only one respondent provided a different answer, despite having an interpreter to mediate communication with researchers. With respect to religion, nine participants reported to be Catholic, which is aligned with the $89.3 \%$ reported in the 2010 census (INEGI, 2010). Compared to Brazil, in the 2010 census (IBGE, 2010), 64.6\% declared themselves Catholic. Although Catholicism still has the largest number of followers, a growth in the quantity of evangelicals and protestants has been observed.

The questions about race, ethnicity, gender, sexual orientation, socioeconomic status, religion beliefs, and age ranges, among others, are transversal to the disability theme (Meekosha (2006); Brazil (2016); Nishida (2016)), since, for instance, a deaf black homosexual man faces even more barriers in society in his daily life. These inclusion matters need to be discussed in order to give visibility (Faucett, 2017) to people who are left aside because society does not know how or does not want to find a way to provide the same level of attention and opportunities as to the mainstream persons.

The deaf adults interviewed reported they do not receive government's financial support; however, the four parents mentioned having this support for their young deaf children. An explanation for this may be that this year the government published the Pension Program for the Welfare of People with Permanent Disabilities (Mexico (2020)) which did not exist previously.

As we noted in previous user research and from specialized literature, deaf participants prefer to be referred to as people who are deaf instead of people with a hearing disability or other designation. According to Ferrigon (2019), there is a controversial discussion on whether educators and researchers should use person-first language (PFL) or identity-first language (IFL) when referring to different groups of people with disabilities, defining both terms as follows: "A person who chooses IFL acknowledges that disability is intertwined into their identity, where as a PFL proponent can choose to focus on the person that is not defined by their limitations". Although Ferrigon (2019) affirms deaf communities prefer IFL, the author also recommends asking individuals how they prefer to be called and referred to.

The three deaf respondents reported they use Whatsapp, Facebook and Instagram more frequently. Our research was conducted before social distancing was imposed due to the Covid-19 pandemic, so technology for communication was more restricted to social networks. Now a variety of options
Table 5. Cultural characteristics of deaf community in Mexico according to respondents.

\begin{tabular}{|c|c|}
\hline Category & Respondents' answers \\
\hline $\begin{array}{l}\text { Culture and } \\
\text { communica- } \\
\text { tion }\end{array}$ & $\begin{array}{l}\text { "Touch to ask someone to talk"; } \\
\text { "Smartphone with vibration"; "Proximity } \\
\text { (talk in the same space, not yell to the other } \\
\text { room)"; "Communication"; "Concern of } \\
\text { whether someone is speaking about } \\
\text { him/her'; "Deafness is a disability with dif- } \\
\text { ferences between cultures"; Diversity; "If } \\
\text { she doesn't manage to communicate, she } \\
\text { isolates herself from others" (2); "They ges- } \\
\text { ture very much"; "Among the two deaf } \\
\text { daughters they communicate with each other } \\
\text { really well"; "It is different between siblings, } \\
\text { even if one is hearing and the other is deaf"; } \\
\text { "Sense of humor"; "Dirty jokes"; "Imitate } \\
\text { other deaf persons"; "Way of thinking"; } \\
\text { "Deaf people's rights, LSM is visual so there } \\
\text { are many dirty comments, but I think this is } \\
\text { a positive characteristic" }\end{array}$ \\
\hline $\begin{array}{l}\text { Community } \\
\text { awareness } \\
\text { and identity }\end{array}$ & $\begin{array}{l}\text { "Solidarity among them (other deaf persons), } \\
\text { they protect themselves"; "Solidarity among } \\
\text { them, companionship or friendships"; "Em- } \\
\text { pathy with their peers"; "Gathering with deaf } \\
\text { peers until dawn; discriminate who are not } \\
\text { deaf"; "School only for deaf students"; } \\
\text { "Sport association"; "Churches"; "Feeling } \\
\text { that they don't belong among hearing per- } \\
\text { sons"; "Somehow vulnerable"; "They feel } \\
\text { like they deserve people to do things for } \\
\text { them, including the older ones" }\end{array}$ \\
\hline $\begin{array}{l}\text { Visual atten- } \\
\text { tion and per- } \\
\text { ception }\end{array}$ & $\begin{array}{l}\text { "Relationship with lighting"; "They are very } \\
\text { attentive"; "They are aware of the problems } \\
\text { occuring around them, they easily perceive } \\
\text { emotions"; "Attention to their surrounding"; } \\
\text { "Very observing"; "They can concentrate } \\
\text { very much on a task"; "Good spatial loca- } \\
\text { tion": "Good to draw images" }\end{array}$ \\
\hline
\end{tabular}

and tools are being used, so one participant reported to use Zoom to communicate with deaf friends who are signers. Additionally, deaf participants did not know of any ASLP systems, neither in LSM nor in other SL. They were curious but interested in knowing whether there were any apps that could translate to or from their natural languages.

From the perspective of the eleven interviewed individuals, their perception on the cultural characteristics of their country is mostly related to history and traditions, tourism and food. Categorized broadly, any country could be described similarly. However, participants reported specific examples (e.g., Day of the Dead, archaeological sites, pyramids, mole poblano, chile en nogada) of culture in Mexico. Thus, for example, how the Day of the Dead is celebrated in Mexico has transcended the country, due in part to its appearance in recent global movies. As such, it merits further research as it might help in obtaining a contrasting external view of Mexican culture as a

\footnotetext{
${ }^{10}$ Ley Federal para Prevenir y Eliminar la Discriminación. 2018. http://www.diputados.gob.mx/LeyesBiblio/pdf/262_210618.pdf
} 
foreigner, one can realize that what someone knows about another culture may be a restricted and narrowed view based on media imagery.

We used the concepts of the Cultural Viewpoint Metaphors (CVM) (Salgado, Leitão and De Souza (2013)) design tool to analyze the deaf signers' communication experience living in an oral-spoken world. Considering "the domestic traveler metaphor", deaf signers would have an experience of communication opposite to the current one, where their visuospatial language would be the dominant one. As explained by Salgado, Leitão and De Souza (2013), the domestic traveler metaphor comprises situations of cultural isolation, not because deaf persons are completely unaware of the "foreign culture" (the hearing culture), but because they cannot communicate using SL in a world that communicates through written and spoken language; therefore, most of the time deaf signers experience life isolated within the deaf community. With respect to "the observer at a distance" and "the guided tour visitor", we found that deaf signers experience the same communication barriers in situations in which they cannot actively have a conversation, to question, critique, give their opinions. Therefore, they do not feel autonomous because of the need of a third (hearing) person to support communication. In "the foreigner with translator metaphors", a human SL interpreter is helping the communication among a deaf signer and a non-signer; however, also in this case they would need third persons' support. Lastly, "the foreigner without translator metaphor" delivers similar communication experience for deaf signers as the second and third metaphors do, with the difference of not being able to either receive or provide information. Based on the eleven participants' report, we found that positive experiences of communication occur in situations having "the domestic traveler metaphor" and "the foreigner with translator metaphors", in order of preference.

Concerning the values (Pereira and Baranauskas (2015)) reported by the interviewed participants, we observed the prevalence of values towards society and deaf community (e.g., respect, love, discipline, equality and equity, solidarity, communication), values of personal level (e.g., honesty, bravery, empathy, self-esteem), and self-centered values (e.g., "myself", "my children", rebellion (as not obeying)). From these, we noticed a conflict between the self-centered values of two participants and the others, such as, "my children" compared to equality and equity, and rebellion compared to discipline. Other than that, both posed values mostly related to family matters.

Finally, one of the limitations of our work concerns communication issues, since the lead researcher's first language was not Spanish and was not a fluent LSM user. This was mitigated by having contact with deaf community in other activities, besides research. Another limitation was the use of a metaphor artifact, which caused some difficulties for participants to understand what was being asked as examples. In a recent study, Edwards et al. (2021)) compared metaphor comprehension among deaf and hearing students, reporting a better understanding of nonliteral language among hearing participants. Based on that, further reflection on the continuity of using this approach should be weighted.

\section{Conclusion}

We have been researching the various issues involved in the codesign of ASLP systems. One broad aim of our work has been to determine whether variations exist in the basic needs of communities of deaf signers depending on the countries where they live, more specifically considering the contexts of deaf communities in Mexico and Brazil. The first stage towards this goal is to characterize the deaf communities in both countries. In this paper, we report our findings from user research regarding the deaf communities in the Mexican context.

Concerning the cultural characteristics of the deaf community in Mexico, we can trace a parallel from a literature review and findings from our interviews, regarding the diversity within deaf culture, the influence of written language on SL, the officially recognized SL associated with low knowledge about deaf culture by the dominant hearing society. Moreover, we noticed very similar reports from what we have been learning for several years of conducting user studies in Brazil, a strong sentiment of belonging in a (deaf) culture which shares the same preference for a mode of communication (in this case, SL), strong community awareness and identity, and a quality of visual attention and perception. These findings meet our broader research of determining possible variations in the basic needs of deaf signers, depending on the countries where they reside. One of our research contributions is to shed light on this path we chose to pursue.

Observing findings through the lenses of the theory of culture of Hall (1990), posing the ASLP systems' design perspective in the three levels, as suggested by Stamper et al. (2000), we mostly are aware of formal and informal perceptions of participants. From a formal stance, we obtained references from laws, census, literature, and school rules; from an informal angle, we observed positive influences of deaf teachers on deaf students and the support they get from their families. The technical aspect only was raised when specifically asked to participants through the examples given of social networks and real-time communication solutions.

Furthermore, based on findings from the cultural viewpoint metaphors, we argue in favor of deaf signers' autonomy, stressing the importance of the design of ASLP systems that can serve as an interface between people from the same country who use different modes of communication. Complementarily, the values of equality and equity, solidarity, communication, and self-esteem are supportive for the design of ASLP systems, since deaf signers are encouraged to use their natural language to communicate everywhere they need and wish to go. With respect to our respondents' values, we still wish to meet the respondents with an unordered list 
of values to discuss with them how we can relate those with the design of ASLP systems and verify whether values still hold or are changed.

As a continuity of this work, we are using the socially aware design approach (Baranauskas (2009)) to codesign ASLP systems with seven participants who were interviewed in this investigation. We already finished the first phase of the interaction design life cycle, having a socio-cultural guideline list organized into semantic levels (from technical to social aspects in the technology design) as a final deliverable.

\section{Acknowledgements}

This research is part of a larger project which was approved by the Ethics Committee (CAAE 18708619.2.0000.8088) of the Universidade Federal de Rondonópolis. We would like to thank professionals and participants of "La Casa del Sordo" and "CAM Jean Piaget", both from Puebla, México. Also, we thank - in the name of Susana de la Torre Reyes - the "Directoria de Educación Especial de la Secretaria de Educación de Puebla (SEP)" for the support and openness to the research.

\section{References}

Baranauskas, M.C.C. (2009). Socially aware computing. In: Proceedings of VI International Conference on Engineering and Computer Education (ICECE 2009), 1-5.

Bragg, Danielle; Koller, Oscar; Bellard, Mary; Berke, Larwan; Boudreault, Patrick; Braffort, Annelies; Caselli, Naomi; Huenerfauth, Matt; Kacorri, Hernisa; Verhoef, Tessa; Vogler, Christian; Morris, Meredith Ringel. (2019). Sign Language Recognition, Generation, and Translation: An Interdisciplinary Perspective. In The 21st International ACM SIGACCESS Conference on Computers and Accessibility (ASSETS '19). Association for Computing Machinery, New York, NY, USA, 16-31. DOI: $10.1145 / 3308561.3353774$.

Bragg, Danielle; Morris, Meredith Ringel; Vogler, Christian; Kushalnagar, Raja; Huenerfauth, Matt; Kacorri, Hernisa. (2020). Sign Language Interfaces: Discussing the Field's Biggest Challenges. In Extended Abstracts of the 2020 CHI Conference on Human Factors in Computing Systems (CHI EA '20). Association for Computing Machinery, New York, NY, USA, 1-5. DOI: 10.1145/3334480.3381053.

Brazil. (2015). Brazilian Law for Inclusion of Persons with Disabilities. Lei Brasileira de Inclusão da Pessoa com Deficiência. Lei $\mathrm{n}^{\circ}$ 13.146, de 2015. Available online (http://t.ly/Ev4z), retrieved September 21, 2020.

Brazil. (2016). Conference National Rights of the Person with Disabilities. In: Anais da $4^{\text {a }}$ Conferência Nacional dos Direitos da Pessoa com Deficiência, Maio. Available online (http://t.ly/s7Kv), retrieved on September 21, 2020.

Cook, Albert M.; Polgar, Jan Miller. (2008). Cook and Husseys's Assistive Technologies: Principles and Practice. 3rd ed., Elsevier.
CRPD. (2006). Convention on the Rights of Persons with Disabilities. Available online (http://bit.ly/39q4EQ8), retrieved on October 2, 2020.

Cruz-Aldrete, Miroslava. (2008). Gramática de la Lengua de Señas Mexicana. Tesis de doctorado en Lingüística, Centro de Estudios Lingüísticos y Literarios-El Colegio de México, México.

Cruz-Aldrete, Miroslava Serrano, Julio. (2018). La Comunidad Sorda Mexicana. Vivir entre varias lenguas: LSM, ASL, LSM, Español, Inglés, Maya. Convergencias. Revista de Educación. Vol. 1, N 2, 2018. (pp. 83-102). Editorial Facultad de Educación. UNCuyo. Mendoza.

Dyer, Annabella; MacSweeney, Mairéad; Szczerbinski, Marçin; Green, Louise; Campbell, Ruth. (2003). Predictors of Reading Delay in Deaf Adolescents: The Relative Contributions of Rapid Automatized Naming Speed and Phonological Awareness and Decoding, The Journal of Deaf Studies and Deaf Education, Volume 8, Issue 3, July 2003, Pages 215-229. DOI: $10.1093 /$ deafed/eng012.

Edwards, L., Marschark, M., Kronenberger, W.G. Crowe, K.; Walton, D. Inferencing Abilities of Deaf College Students: Foundations and Implications for Metaphor Comprehension and Theory of Mind. J Dev Phys Disabil 33, 233-258 (2021). DOI: 10.1007/s10882-020-09746-w.

Faucett, Heather A.; Ringland, Kate E.; Cullen, Amanda L. L.; Hayes, Gillian R. (2017). (In)Visibility in Disability and Assistive Technology. ACM Transactions on Accessible Computing, Vol. 10, No. 4, Article 14. Publication date: October.

Ferrigon, P. (2019). Person-First Language vs. Identity-First Language: An examination of the gains and drawbacks of Disability Language in society. Journal of Teaching Disability Studies. Available online (http://t.ly/QGbM), retrieved on September 23, 2020.

Gugenheimer, Jan; Plaumann, Katrin; Schaub, Florian; San Vito, Patrizia Di Campli; Duck, Saskia; Rabus, Melanie; Rukzio, Enrico. (2017). The Impact of Assistive Technology on Communication Quality Between Deaf and Hearing Individuals. CSCW 2017, February 25-March 1, 2017, Portland, OR, USA. DOI: $10.1145 / 2998181.2998203$.

Hall, Edward T. (1990). The Silent Language. Anchor Books Editions.

IBGE. (2010). Instituto Brasileiro de Geografia e Estatística. Available online (https://www.ibge.gov.br), retrieved on September 7, 2020.

INEGI. (2010). Instituto Nacional de Geografía y Estadística de México. 2010. Available online (https://www.inegi.org.mx/programas/ccpv/2010), retrieved on September 7, 2020.

Kacorri, Hernisa; Huenerfauth, Matt; Ebling, Sarah; Patel, Kasmira; Willard, Mackenzie. (2015). Demographic and Experiential Factors Influencing Acceptance of Sign Language Animation by Deaf Users. In Proceedings of the 17th International ACM SIGACCESS Conference on Computers \& Accessibility (ASSETS '15). Association for Computing Machinery, New York, NY, USA, 147-154. DOI: $\underline{10.1145 / 2700648.2809860 .}$. 
Meekosha, Helen. (2006). What the Hell are You? An Intercategorical Analysis of Race, Ethnicity, Gender and Disability in the Australian Body Politic. Journal Scandinavian Journal of Disability Research, Volume 8, 2006 - Issue 23: Gender and Disability. Available online (http://t.ly/DPuO), retrieved on September 21, 2020.

México. (2005). General Law of Persons with Disabilities. Revoked by the Ley General de Inclusión de Personas con Discapacidad (LGPID), in 2011. Available online (http://www.diputados.gob.mx/LeyesBiblio/pdf/LGIPD_120718.pdf), retrieved on September 6, 2020.

México. (2020). Reglas de Operación del Programa Pensión para el Bienestar de las Personas con Discapacidad Permanente, para el ejercicio fiscal 2020. Diario Oficial, Miércoles 5 de febrero de 2020, Secretaria de Bienestar. Available online (http://t.ly/s66V), retrieved on September 6, 2020.

Mirta, Sophie; Posarac, Aleksandra; Vick, Brandon. (2013). Disability and Poverty in Developing Countries: A Multidimensional Study. World Development Vol. 41, pp. 1-18, 2013. DOI: $10.1016 /$ j.worlddev.2012.05.024.

Nishida, Akemi. (2016). Understanding political development through an intersectionality framework: Life stories of disability activists. Disability Studies Quarterly, Vol 36, No 2. Available online (http://t.ly/JrHh), retrieved on September 21, 2020.

Paim, Polianna; Prietch, Soraia; Duarte, Anderson. (2018). CoDesign in the Exploratory Phase of an Assistive Technology product Design to support the Teaching-Learning Process of Brazilian-Portuguese Language for Visual Persons. In Proceedings of the 17th Brazilian Symposium on Human Factors in Computing Systems (IHC 2018). Association for Computing Machinery, New York, NY, USA, Article 12, 1-9. DOI: 10.1145/3274192.3274204.

Paim, Polianna dos Santos; Prietch, Soraia Silva. (2019a). Semiotic ladder artifact to design an assistive technology product for people who are deaf. In Proceedings of the IX Latin American Conference on Human-Computer Interaction (CLIHC '19). Association for Computing Machinery, New York, NY, USA, Article 21, 1-5. DOI: 10.1145/3358961.3358982.

Paim, Polianna dos Santos; Prietch, Soraia Silva. (2019b). Communicability evaluation of video-exam in libras of the
ENEM platform. In Proceedings of the 18th Brazilian Symposium on Human Factors in Computing Systems (IHC '19). Association for Computing Machinery, New York, NY, USA, Article 19, 1-11. DOI: 10.1145/3357155.3358478.

Pereira, Roberto; Baranauskas, Maria Cecília Calani. (2015). A value-oriented and culturally informed approach to the design of interactive systems. International Journal of Human-Computer Studies, 80, 6682. DOI: 10.1016/j.ijhcs.2015.04.001.

Petitta, Giulia; Dively, Valerie; Halley, Mark; Holmes, Marc; Nicodemus, Brenda. (2018). "My Name is A-on-thecheek": Managing Names and Name Signs in American Sign Language-English Team Interpretation. Pages 205218, 23 Oct 2018. DOI: 10.1080/00277738.2018.1490521.

Power, Des; Leigh, Gregory R. (2000). Principles and Practices of Literacy Development for Deaf Learners: A Historical Overview. The Journal of Deaf Studies and Deaf Education, Volume 5, Issue 1, January 2000, Pages 3-8. DOI: $10.1093 /$ deafed/5.1.3.

Prietch, S. S., Filgueiras, L. V. L. (2013). One Assistive Technology does not fit all Educational Strategies: A Reflection on Deaf Students in Mainstream Classroom. Workshop on Rethinking Universal Accessibility: A broader approach considering the digital gap, INTERACT 2013, Cape Town, South Africa.

Salgado, L.C.C.; Leitão, C.F.; de Souza C.S. (2013). A Journey Through Cultures: Metaphors for Guiding the Design of Cross-Cultural Interactive Systems, Human-Computer Interaction Series, Springer-Verlag. DOI: 10.1007/978-14471-4114-3_1.

Shinohara, Kristen; Wobbrock, Jacob O. (2011). In the shadow of misperception: assistive technology use and social interactions. In Proceedings of the SIGCHI Conference on Human Factors in Computing Systems (CHI '11). Association for Computing Machinery, New York, NY, USA, 705-714. DOI: 10.1145/1978942.1979044.

Stamper, Ronald; Liu, Kecheng; Hafkamp, Mark; Ades, Yasser. (2000). Understanding the roles of signs and norms in organizations - a semiotic approach to information systems design. Journal Behaviour \& Information Technology, Volume 19, 2000 - Issue 1. DOI: 10.1080/014492900118768. 